\title{
Environmental Characteristics of Children's Neighborhood Activities
}

\author{
Heng Zhang ${ }^{1}$, Min-Jin Li ${ }^{2}$ \\ ${ }^{1,2}$ Department of Architecture, \\ National Cheng Kung University, Taiwan \\ changlin@mail.ncku.edu.tw
}

\begin{abstract}
Environmental characteristics affecting children's physical abilities and health are worth understanding. The purpose of this study is to identify neighborhood environmental characteristics that influence children's activities and assess the friendliness of Taiwanese communities toward children's activities. Conditions are observed on the basis of five environmental characteristics: safety, amenity, accessibility, sociability, and attractiveness. The three communities studied have different combinations of street patterns and land use which, in turn, are conducive to different children's activities. These findings are valuable for community design aimed at promoting children's activities.

Keywords: Neighborhood Characteristics, Children's Activities, Community Design, Street Pattern

eISSN 2514-751X @ 2017 The Authors. Published for AMER ABRA by e-International Publishing House, Ltd., UK.. This is an open access article under the CC BY-NC-ND license (http://creativecommons.org/licenses/by-ncnd/4.0/). Peer-review under responsibility of AMER (Association of Malaysian Environment-Behaviour Researchers), ABRA (Association of Behavioural Researchers on Asians) and CE-Bs (Centre for EnvironmentBehaviour Studies), Faculty of Architecture, Planning \& Surveying, Universiti Teknologi MARA, Malaysia.

https://doi.org/10.21834/aje-bs.v2i3.187
\end{abstract}




\subsection{Introduction}

Over the past few decades, the number of children engaged in outdoor activities has declined all over the world. Rather than go outside, children prefer to play with computers or watching TV at home. For those who do play outside the home, most limit their play to areas near the home or on playgrounds because of insufficient outdoor recreation facilities. Children's play normally relies on structural facilities because of a lack of unstructured outdoor play opportunities (de Vries et al., 2010; Staempfli, 2009; Valentine \& McKendrick, 1997). Moreover, more children today are taken to school by their parents, and only a small percentage of children walk or cycle to school on their own. Research has indicated that this growth in car use significantly reduces children's daily activity (Cooper, Page, Foster, \& Qahwaji, 2003) Walking or cycling to school has long been an overlooked source of daily physical activity for children (de Vries et al., 2010), and there is considerable concern that low levels of physical activity may predispose children to obesity and chronic disease in later life (Cooper, Page, Foster, \& Qahwaji, 2003).

Play is a natural instinct among children, who learn and experience various biological, psychological, and social changes via play. By participating in extracurricular activities, children can put these developing skills into action (Valentine \& McKendrick, 1997). Physical and mental development in childhood has a great impact on future life (Howie, Lukacs, Pastor, Reuben, \& Mendola, 2010). Nevertheless most research focus on playgrounds for children, and pays little attention to variety in children's play. Children can play anytime and anywhere, but we should take efforts to improve the play environment first.

The physical environment of the neighborhood is an important factor in children's activities. Previous studies have found environmental characteristics, such as accessibility and walkability, to have an effect on children's physical ability and health. Understanding the relationship between children's activities and the neighborhood's environmental characteristics is thus imperative to facilitating children's physical and mental development. However, few studies have explored this topic comprehensively. The purpose of this study is to identify environmental characteristics in the neighborhood that affect children's activities and assess the friendliness of Taiwanese communities toward children's activities.

\subsection{Literature Review}

\subsection{Neighborhood Environment Characteristics}

The neighborhood environment should be supportive, accessible, and functional: supportive denotes inclusion of venues (e.g., parks and open spaces) for different social activities and opportunities for recreational physical activity (Binns et al., 2009); accessible denotes the provision of smooth sidewalks, broad passages and sufficient parking space; and functional denotes management to promote neighborhood security (Huang, 2006). 


\subsection{Children's environment}

Though environmental characteristics appear to play a role in determining behaviour in children, few studies have examined children's needs in the built environment. Most of the research available focuses on the characteristics of playgrounds, but not on neighborhood environments. This study combines playground and environmental characteristics to discover new needs.

\section{Safety (traffic and personal safety)}

Most research has focused on safety as the most important concern, leading to a huge decrease in children's outdoor activities. Safety can be differentiated into two aspects: physical and mental. The increase in car usage has contributed to an environment designed for drivers rather than pedestrians, resulting in a high number of traffic accidents every year. Parental anxiety in regards to traffic safety has grown, resulting in many parents restricting their children's outdoor play (Panter, Jones, van Sluijs, \& Griffin, 2010a; Puglisi, Okely, Pearson, \& Vialle, 2010). Poor neighbourhood design also contributes to crime and it has been suggested that unsafe neighborhoods discourage leisure activities and unstructured play and predispose children to more sedentary activity (Veugelers, Sithole, Zhang, \& Muhajarine, 2008). Parents who fear for their children's safety at the hands of strangers have also been found to restrict their children's opportunities to play outdoors (Valentine \& McKendrick, 1997).

\section{Amenity (openness and aesthetics)}

A comfortable neighborhood should feature openness and aesthetics. Openness in an environment can offer clear visibility, which could lower the fear of crime, and create opportunities for interaction. The aesthetics of an environment refers to the general pleasantness of the surroundings - well kept houses and gardens, without graffiti and rubbish (Saelens et al., 2003; Timperio et al., 2004).

\section{Accessibility (convenience and walkability)}

High accessibility means more opportunities to walk rather than drive. Features of an accessible neighbourhood include good access to supermarkets, shops, post boxes, and public facilities. Access to parks, playgrounds and recreational facilities has also been linked to increased physical activity and less sedentary activity (Hume, Salmon, \& Ball, 2005; Veugelers et al., 2008). Furthermore, high walkability was positively related to increased walking and cycling among children (Holt et al., 2008; Holt et al., 2009).

\section{Sociability (conduciveness to gathering and staying)}

Research has indicated that a lack of friends is a barrier to a child's participation in physical activity (Puglisi, Okely, Pearson, \& Vialle, 2010), which highlights the importance of sociability to children. It offers children opportunities to learn social skills, including selfexpression, communication, sharing, and compromising. Sociability also provides opportunities for role play which helps children learn emotional control. In the context of a neighborhood environment, sociability is a measure of the opportunity for people to gather, which implies opportunities for children to engage in social interaction (Hume, Salmon, \& 
Ball, 2005).

\section{Attractiveness (variability, challenge and complexity)}

Environmental attractiveness is conducive to raising children's interest to play (Ting-Ju Lin \& Yann-Jou Lin, 2008). High variability, challenge and complexity are indispensable characteristics of attractiveness, but these factors are often neglected in neighborhood design. An environment with high variability is full of surprises, while challenge provides children with an opportunity to feel accomplishment and complexity creates a sense of mystery.

\subsection{Methodology}

\subsection{Study Site}

This study was conducted in three neighborhoods in Tainan City (Simen, Jinhwa, and Huwei), in southern Taiwan. Tainan was the ancient capital of Taiwan and was the area developed earliest. The three neighborhoods were selected for their proximity to schools, and vary in street patterns and land use (The three maps in Fig.1 are drawn to the same scale). Simen is one of the oldest parts of Tainan. This neighbourhood is very close to Anping harbor, which was the center of Tainan's early development. Lacking urban planning, people built houses according to their needs, leaving spaces between houses to turn into passages. These narrow and winding passages have been preserved to the present day, and impede clear line of sight from street to street.

Jinhwa was redeveloped in the 1970s, and most buildings here are apartment buildings of 4-6 stories. The neighborhood is mixed use with a high population density, featuring a concentration of commercial usage along the main corridor. The activities of the community development association have instilled a strong sense of community among residents.

Huwei is a relatively modern purely-residential neighborhood featuring 3-4 story row houses, some of which share a courtyard.. Streets are laid out on a grid pattern, and main roads are 12-20 meters wide.

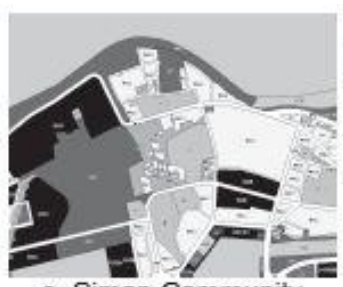

a. Simen Community

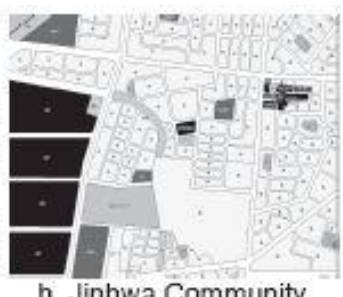

b. Jinhwa Community

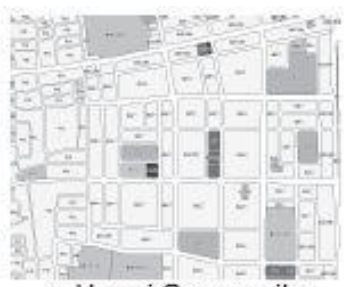

c. Huwei Community

Figure 1: Site Map 


\subsection{Subject}

This study focused on children in these neighborhoods aged between 6 and 12-years old. These elementary school students are capable of certain independent activities, and are thus more likely to have a radius of action for their daily activities that corresponds with their neighborhood.

\subsection{Method}

This study employed a qualitative case study approach to gain a holistic understanding of the children's environment. Environmental behavior researchers normally adopt the observation method which permits researchers to study people in their native environment and provides an innovative means of assessing behavior linked to the specific physical characteristics of a given neighborhood.

Researchers walked through the neighborhoods after school was over and collected environmental characteristics by neighborhood observation. An assessment tool with five environmental characteristics was applied to observe the conditions of children's activities in the three neighborhoods.

\subsection{Results and Discussions}

\subsection{Structure of neighborhood environmental characteristics for children's activities}

A review of the literature shows that essential environmental characteristics affecting children's activities in their neighborhood include: (1) safety (traffic safety and fear of crime); (2) amenity (openness and aesthetics); (3) accessibility (convenience and walkability); (4) sociability (conduciveness to gathering and staying); and (5) attractiveness (variability, challenge and complexity). A structure, consisting of these environmental characteristics, is proposed for assessing a neighborhood's friendliness toward children's activities (e.g. Fig. 2).

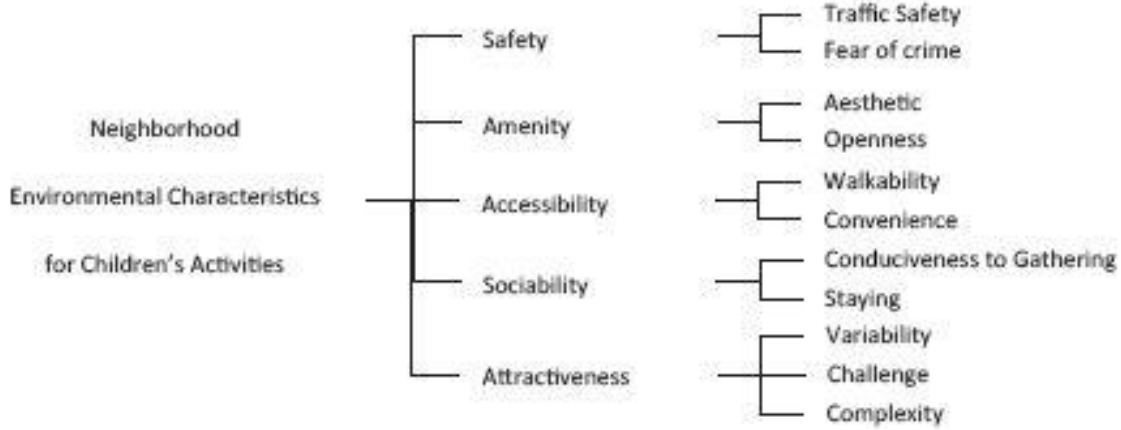

Figure 2: Neighborhood Environment Characteristics for children's activities structure 


\subsection{Results}

Observation shows that the Simen community, with its organic street pattern, perform better in terms of traffic safety, variability and visual complexity (Table1). The narrowness of the streets prevents cars from entering and even forces scooter drivers to slow down. Thus parents feel comfortable allowing their children to play outside in the street. The street scale here is suitable for children's activities, and they are free to run around without concern for vehicles. The winding streets and the changing pavements provide a constantly changing scene full of challenge and mystery, thus raising children's interest to go outside (e.g. Fig3.$a, b)$.

The Jinhwa community, with its grid pattern and mixed land use is better for everyday convenience and sociability (Table 1). The diversity and convenience of the shops gives children the chance to walk about without being driven, thus promoting some extra physical activity. Two parks are located in the neighborhood (close to the residential area), and are easily accessible to children. Lots of green open space has been set aside by residents, where children can gather together (e.g. Fig. 3-c, d).

The Huwei community, with its grid pattern and residential land use performs better in aesthetics, walkability and reduced fear of crime. Houses here were built recently, with tidy facades and plenty of trees. The whole environment conveys a comfortable atmosphere, which is conducive to children's mental development. The roads here are straight and broad, allowing for clear visibility and reducing fear of crime, thus increasing opportunities for children to play outdoors (e.g. Fig.3-e, f). Organic street patterns contribute to safety and attractiveness. Grid patterns and mixed land provide greater convenience and encourage children's social communication. Grid patterns and residential land use improve safety, aesthetics, and walkability.

Table 1: Dominant environmental characteristics for children's activities in three communities

\begin{tabular}{|c|c|c|c|c|}
\hline \multicolumn{2}{|c|}{ Environment Characteristics } & Sinen & Jinhwa & Huwei \\
\hline \multirow{2}{*}{ Safety } & Traffic Safety & (9) & - & - \\
\hline & Fear of crime & - & - & (9) \\
\hline \multirow{2}{*}{ Amenity } & Aesthetic & - & - & (9) \\
\hline & Openess & - & - & - \\
\hline \multirow{2}{*}{ Accessibility } & Walkability & - & - & (9) \\
\hline & Convenience & - & (9) & - \\
\hline \multirow{2}{*}{ Sociability } & Conduciveness To Gathering & - & (2) & - \\
\hline & Staying & - & (9) & - \\
\hline \multirow{3}{*}{ Attractivenes } & Variability & (9) & - & - \\
\hline & Challenge & - & - & - \\
\hline & Complexity & (9) & - & - \\
\hline
\end{tabular}

The two groups of children showed different preference in terms of neighborhood 
environment. The children aged 6-9 primarily play at a specific playground with clear boundaries, and are usually accompanied by their parents or other family members. The 9 12 year old children primarily used the sports field as their main play space, and also engaged in activities on the street or other neighborhood spaces. The older children were much more independent and usually play with friends or peers, resulting in a higher degree of social interaction.

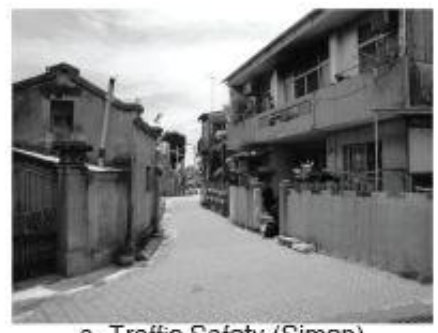

a. Traffic Safety (Simen)

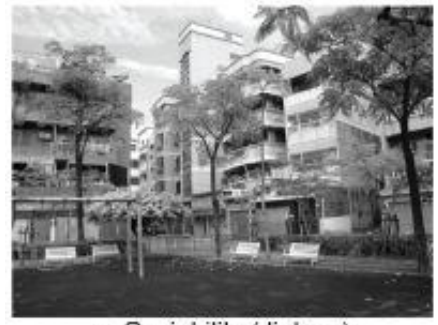

c. Sociability (Jinhwa)

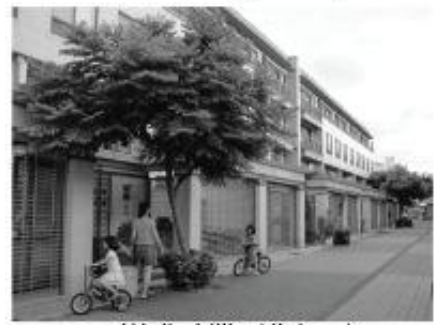

e. Walkability (Jinhwa)

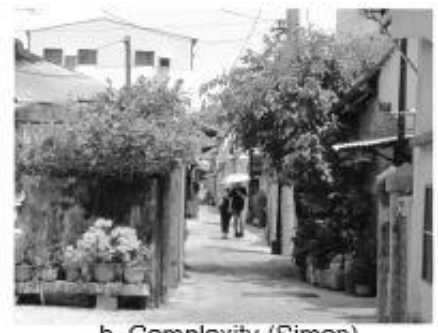

b. Complexity (Simen)

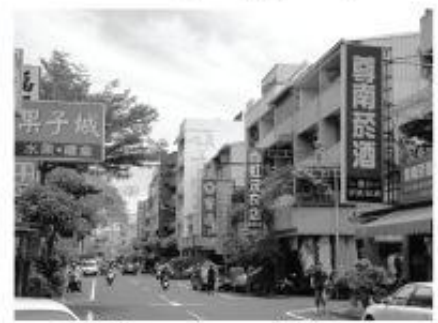

d. Convenience (Jinhwa)

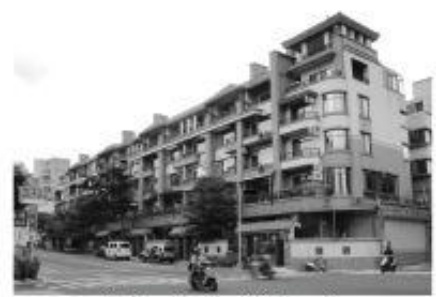

f. Aesthetic (Jinhwa)

Figure 3: Streetscapes

\subsection{Discussion}

The narrowness of the streets in Simen makes them feel unsafe to an adult, but to children the scale feels larger and provides a source of adventure. However, few planners consider the viewpoint of children and normally neglect their needs. The roads in Huwei are highly 
walkable, but the width of the roads is also conducive to cars driving at high speed through the neighborhood, thus raising obstacles to children playing in the streets. There're also lots of parks in Huwei, but they are located on the edge of the neighborhood and are thus difficult for children to access unless accompanied by their parents, thus depriving children the chance to learn to be independent.

Neighborhood observation revealed that "challenge" is an important characteristic which is usually ignored in the planning and design of neighborhood environments. Planners aiming to raise the attractiveness of neighborhood environments should consider the value of "challenge".

Some studies have indicated that residents increasingly withdraw from local public places has a correlation with lacking a local identity. In their context, the community is functionally deficient: their neighborhood is just where their house happens to be located, and they prefer to stay in the privacy of their homes or to leave the area entirely in search of recreation (Buchecker, 2009). Our research found some neighborhood characteristics are conducive to children's activities, and it also revealed that joint or group activities between children can improve the quality of social interaction. Therefore, a properly-designed neighborhood environment, such as: increased mobility and spaces for informal interaction (Buchecker, 2009; Owens, 1997), can promote children's social interaction. These findings are consistent with the results of previous research.

\subsection{Conclusion}

Based on a review of the relevant literature, this study develops a structure to assess environmental characteristics for children's activities within their neighborhoods. This structure was then used to evaluate the friendliness of three Taiwanese communities toward children's activities. A major finding is that specific environmental characteristics arise from the various street patterns and land use in different communities, which in turn are conducive to different types of children's activities. A dynamic community with superior children's activities correlates with the relevant environmental characteristics. Planners should do more to incorporate these environmental characteristics for children's activities into neighborhood planning. The methodology used and the use of the grid table will contribute to the future development of environmental psychology research in Western and Asian settings.

\section{Acknowledgement}

This study was supported by a grant from the National Science Council, Taiwan, Republic of China, under the project NSC96-2511-S006-002MY3. 


\section{References}

Binns, H. J., Forman, J. A., Karr, C. J., Osterhoudt, K., Paulson, J. A., Roberts, J. R., et al. (2009). The Built Environment: Designing Communities to Promote Physical Activity in Children. Pediatrics, 123(6), 1591-1598.

Buchecker, M. (2009). Withdrawal from the Local Public Place: Understanding the Process of Spatial Alienation. Landscape Research, 34(3), 279-297.

de Vries, S. I., Hopman-Rock, M., Bakker, I., Hirasing, R. A., \& van Mechelen, W. (2010). Built Environmental Correlates of Walking and Cycling in Dutch Urban Children: Results from the SPACE Study. International Journal of Environmental Research and Public Health, 7(5), 2309-2324.

Holt, N. L., Cunningham, C. T., Sehn, Z. L., Spence, J. C., Newton, A. S., \& Ball, G. D. C. (2009). Neighborhood physical activity opportunities for inner-city children and youth. Health \& Place, 15(4), 1022-1028.

Holt, N. L., Spence, J. C., Sehn, Z. L., \& Cutumisu, N. (2008). Neighborhood and developmental differences in children's perceptions of opportunities for play and physical activity. Health \& Place, 14(1), 2-14.

Howie, L. D., Lukacs, S. L., Pastor, P. N., Reuben, C. A., \& Mendola, P. (2010). Participation in Activities Outside of School Hours in Relation to Problem Behavior and Social Skills in Middle Childhood. Journal of School Health, 80(3), 119-125.

Huang, Y. -J. (2006). The relationship between outdoor space forms and users' place attachment. Unpublished master's thesis, National Cheng Kung University, Tainan City, Taiwan.

Hume, C., Sahnon, J., \& Ball, K. (2007). Associations of children's perceived neighborhood environments with walking and physical activity. American Journal of Health Promotion, 21(3), 201-207.

Hume, C., Salmon, J., \& Ball, K. (2005). Children's perceptions of their home and neighborhood environments, and their association with objectively measured physical activity: a qualitative and quantitative study. Health Education Research, 20(1), 1-13.

Lin, T.-J. \& Lin, Y.-J. (2008) Application of Agent-Based Simulation to Investigate Behavior on Playground. Taiwanese Journal of Leisure and Recreation.

Owens, P. E. (1997). Adolescence and the cultural landscape: Public policy, design decisions, and popular press reporting. Landscape and Urban Planning, 39(2-3), 153-166.

Panter, J. R., Jones, A. P., van Sluijs, E. M. F., \& Griffin, S. J. (2010a). Attitudes, social support and environmental perceptions as predictors of active commuting behaviour in school children. Journal of Epidemiology and Community Health, 64(1), 41-48.

Puglisi, L. M., Okely, A. D., Pearson, P., \& Vialle, W. (2010). Barriers to increasing physical activity and limiting small screen recreation among obese children. Obesity Research \& Clinical Practice, 4(1), 33-40.

Saelens, B. E., Sallis, J. F., Black, J. B., \& Chen, D. (2003). Neighborhood-based differences in physical activity: An environment scale evaluation. American Journal of Public Health, 93(9), 1552-1558.

Staempfli, M. B. (2009). Reintroducing Adventure Into Children's Outdoor Play Environments. Environment and Behavior, 41(2), 268-280. 
Zhang, H., \& Li, M. / Asian Journal of Environmen-Behaviour Studies, ajE-Bs, 2(3), Apr./Jun. 2017 (p.47-56)

Timperio, A., Crawford, D., Telford, A., \& Salmon, J. (2004). Perceptions about the local neighborhood and walking and cycling among children. Preventive Medicine, 38(1), 39-47.

Valentine, G., \& McKendrick, J. (1997). Children's outdoor play: Exploring parental concerns about children's safety and the changing nature of childhood. Geoforum, 28(2), 219-235.

Veitch, J., Salmon, J., \& Ball, K. (2008). Children's active free play in local neighborhoods: a behavioral mapping study. Health Education Research, 23(5), 870-879.

Veugelers, P., Sithole, F., Zhang, S., \& Muhajarine, N. (2008). Neighborhood characteristics in relation to diet, physical activity and overweight of Canadian children. International Journal of Pediatric Obesity, 3(3), 152-159. 